\title{
ANÁLISE DOS PRINCIPAIS IMPACTOS NA PROVISÃO PARA PERDAS ESTIMADAS COM CRÉDITOS DE LIQUIDAÇÃO DUVIDOSA OCASIONADOS PELA IMPLEMENTAÇÃO DA NORMA IFRS 9 EM INSTITUIÇÕES FINANCEIRAS
}

\author{
ANALYSIS OF THE MAIN IMPACTS ON THE PROVISION FOR \\ ESTIMATED LOSSES ON DOUBTFUL ACCOUNTS CAUSED BY THE \\ IMPLEMENTATION OF THE IFRS 9 STANDARD IN FINANCIAL \\ INSTITUTIONS
}

\section{ANÁLISIS DE LOS PRINCIPALES IMPACTOS EN LA PROVISIÓN PARA PÉRDIDAS ESTIMADAS SOBRE RIESGOS CREDITICIOS CAUSADOS POR LA IMPLEMENTACIÓN DE LA NORMA NIIF 9 EN INSTITUCIONES FINANCIERAS}

\author{
Valério Vitor Bonelli ${ }^{1}$ \\ Giovanna Rodrigues Federici ${ }^{2}$ \\ Paulo da Silva Melo ${ }^{3}$ \\ Gleubert Carlos Coliath ${ }^{4}$
}

Artigo recebido em maio de 2021

Artigo aceito em setembro de 2021

\begin{abstract}
RESUMO
O presente trabalho tem como objetivo analisar os principais impactos ocasionados pela implementação das normas internacionais (IFRS) para o cálculo da PECLD - Provisão para Perdas Estimadas com Crédito de Liquidação Duvidosa no percentual de provisão das operações de crédito das instituições financeiras que atuam no Brasil. O referencial teórico aborda os conceitos necessários para o entendimento acerca de crédito e provisão para crédito de liquidação duvidosa. Além disso, são expostos os requerimentos mínimos da Resolução CMN 2.682/99 bem como os requerimentos mínimos da IFRS 9. Para analisar o impacto mencionado, foram analisadas três instituições financeiras que atuam no Brasil, e para tal análise tabulou-se os dados da carteira de crédito (exposição) bem como da provisão nos sites de tais instituições. Por meio de uma metodologia descritiva, comparou-se o percentual de cobertura da provisão em relação à exposição da carteira de crédito dos dados publicados em IFRS e BRGAAP. Observou-se que todas as instituições financeiras analisadas

\footnotetext{
${ }^{1}$ Graduado em Administração, Ciências Contábeis, Mestre em Controladoria e Doutor em Ciências Contábeis pela PUC-SP. Professor na PUC-SP. E-mail: valeriob@uol.com.br.

${ }^{2}$ Graduada em Engenharia Civil pelo IFSP e Graduada em Ciências Contábeis pela PUC-SP. E-mail: giovannarfederici@gmail.com.

${ }^{3}$ Graduado em Ciências Contábeis e Mestre em Ciências Contábeis pela PUC-SP. Professor na PUC-SP. E-mail: psmelo@pucsp.br.

${ }^{4}$ Graduado em Ciências Contábeis, Mestre e Doutor em Ciências Sociais e Mestre em Ciências Contábeis pela PUC-SP. Professor na PUC-SP. E-mail: coliath@ pucsp.br.
}

Refas - ISSN 2359-182X v.8, n.1

Outubro de 2021 
apresentaram exposição e provisão de crédito de liquidação duvidosa na publicação IFRS superior a publicação segundo o BRGAAP (PECLD mínima), conforme expectativa.

Palavras-chaves: IFRS 9. Provisão. Crédito de liquidação de duvidosa. Perda esperada.

\begin{abstract}
This paper aims to analyze the main impacts caused by the implementation of international standards (IFRS) for the calculation of PECLD - Allowance for Estimated Losses with Doubtful Credits in the percentage of allowance for credit operations of financial institutions operating in Brazil. The theoretical framework addresses the concepts needed to understand credit and allowance for doubtful accounts. In addition, the minimum requirements of CMN Resolution 2682/99 are exposed, as well as the minimum requirements of IFRS 9. To analyze the mentioned impact, three financial institutions operating in Brazil were analyzed, and for such analysis, the portfolio data was tabulated. (exposure) as well as provision on the websites of such institutions. Through a descriptive methodology, the percentage of coverage of the provision was compared in relation to the exposure of the credit portfolio of data published in IFRS and BRGAAP. It was observed that all financial institutions analyzed presented exposure and allowance for doubtful accounts in the IFRS publication higher than the publication according to BRGAAP (minimum PECLD), as expected.
\end{abstract}

Keywords: IFRS 9. Provision. Allowance for Loan Losses. Expected loss.

\title{
RESUMEN
}

Este trabajo tiene como objetivo analizar los principales impactos causados por la implementación de normas internacionales (NIIF) para el cálculo de PECLD - Estimación de Pérdidas Estimadas con Créditos Dudosos en el porcentaje de la reserva para operaciones crediticias de las instituciones financieras que operan en Brasil. El marco teórico aborda los conceptos necesarios para comprender el crédito y la provisión para cuentas de cobro dudoso. Además, se exponen los requisitos mínimos de la Resolución CMN 2682/99, así como los requisitos mínimos de la NIIF 9. Para analizar el impacto mencionado, se analizaron tres instituciones financieras que operan en Brasil, y para tal análisis se tabuló la información de la cartera. . (exposición) así como la provisión en los sitios web de dichas instituciones. Mediante una metodología descriptiva, se comparó el porcentaje de cobertura de la provisión en relación a la exposición de la cartera crediticia de los datos publicados en NIIF y BRGAAP. Se observó que todas las instituciones financieras analizadas presentaron exposición y provisión para cuentas de cobro dudoso en la publicación NIIF superior a la publicación según BRGAAP (PECLD mínimo), como se esperaba.

Palabras clave: NIIF 9. Disposición. Estimación para riesgos creditícios. Pérdida esperada.

\section{INTRODUÇÃO}

Ao realizarem operações de crédito (empréstimos), as instituições financeiras passam a ficar expostas ao risco de crédito proveniente de seus clientes. Esse risco de crédito consiste na possibilidade de o cliente não honrar com os compromissos assumidos no contrato de crédito, podendo tornar-se inadimplente. Em decorrência desse risco, o Banco Central do Brasil (Bacen) exigiu que as instituições financeiras passassem a mensurar a expectativa de perda relacionada a uma operação de crédito, denominada provisão para crédito de liquidação duvidosa (PCLD), por meio da implementação da Resolução CMN 2.682/99. 
Esta Resolução institui que as operações de crédito devem ser classificadas em níveis de risco (ratings), que variam de $\mathrm{AA}$ a $\mathrm{H}$ e, para cada rating, é estipulado um percentual mínimo de provisão (CMN, 1999).

No entanto, a partir do ano de 2010, o Brasil passou a utilizar o conjunto de normas contábeis internacionais emitidas pelo IASB: as normas IFRS (International Financial Reporting Standard.

Em 24 de julho de 2014, o IASB (International Accounting Standards Board) publicou a norma IFRS 9, que se aplica a instrumentos financeiros e que veio substituir o IAS 39. No que se refere ao cálculo de provisão para créditos de liquidação duvidosa, a norma IFRS 9 apresenta um novo modelo de impairment, o que resulta no reconhecimento antecipado das perdas de crédito (PwC, 2014).

Com isso, as instituições financeiras necessitam se adequar aos procedimentos contábeis de provisão para créditos de liquidação duvidosa, seguindo duas normas: Resolução $\mathrm{n}^{\circ}$ 2.682, para atender ao Bacen e as normas do IFRS, para fins societários (FONTENELE, 2013).

A questão problema desse trabalho possui enfoque nas alterações estabelecidas pelos órgãos reguladores, procurando responder quais são as principais mudanças na mensuração de provisão para crédito de liquidação duvidosa nas instituições financeiras que atuam no Brasil e que publicam suas demonstrações financeiras seguindo as normas do IFRS? Quais os impactos financeiros, refletidos na conta de provisão para crédito de liquidação duvidosa?

O tema do estudo está relacionado às metodologias de impairment dos instrumentos financeiros, de acordo com a Resolução no 2.682 e a norma IFRS 9. Assim, conhecendo os requerimentos mínimos exigidos pelos reguladores, quanto à mensuração da provisão para devedores duvidosos, será possível realizar a análise dos principais impactos financeiros na conta de Provisão para crédito de liquidação duvidosa gerada pela adoção da IFRS 9.

Academicamente, por meio deste trabalho utilizando uma metodologia qualitativa, será possível visualizar por exemplificação, como os ativos financeiros que apresentam risco de crédito são classificados pela Resolução 2.682 e pela norma IFRS 9. Consequentemente, será demonstrado o impacto financeiro na conta de Provisão para Perdas Estimadas com Crédito de Liquidação Duvidosa.

\section{REFERENCIAL TEÓRICO}

A criação do Banco Central do Brasil se deu a partir da Lei ${ }^{\circ}$ 4.595, de 31 de dezembro de 1964 (também chamada Lei de Reforma Bancária). Antes de sua criação, as funções de autoridade monetária brasileira eram desempenhadas pela Superintendência da Moeda e do Crédito (Sumoc), pelo Conselho Superior da Sumoc, pelo Banco do Brasil e pelo Tesouro Nacional. Em conjunto, esses órgãos exerciam funções peculiares de um banco central. Além da criação do BCB (Banco Central do Brasil), a Lei no 4.595 também extinguiu o Conselho Superior da Sumoc e, em substituição, criou o Conselho Monetário Nacional (CMN) (BCB, 2008).

A principal missão dos bancos centrais é garantir a estabilidade de preços, evitando assim a desvalorização da moeda. Para tanto, considerando o conjunto de atribuições legais e regulamentares, as funções do Banco Central do Brasil são: 
a) formulação, execução e acompanhamento da política monetária; financeiro;

b) controle das operações de crédito em todas as suas formas, no âmbito do sistema

c) formulação, execução e acompanhamento da política cambial e de relações financeiras com o exterior;

d) organização, disciplinamento e fiscalização do Sistema Financeiro Nacional, do Sistema de Pagamentos Brasileiro e do Sistema Nacional de Habitação, e ordenamento do mercado financeiro;

e) emissão de papel-moeda e de moeda metálica e execução dos serviços do meio circulante.

Portanto, para que as instituições financeiras passem a operar no Brasil, estas devem seguir as resoluções instituídas pelo seu órgão regulador: o Banco Central do Brasil.

Em linhas gerais, as instituições financeiras têm as operações de crédito como seu principal produto. Essas operações de crédito nada mais são que linhas de empréstimo fornecidas aos clientes, com a característica de pagamento de principal mais juros e que apresentam risco de crédito associado a elas, uma vez que alguns clientes podem não honrar as condições contratuais do empréstimo, gerando perdas de ativos (despesas) (FONTENELE, 2013).

Visando conservar o Sistema Financeiro Nacional o governo desenvolveu regulamentações referentes ao provisionamento de perdas das carteiras de crédito das instituições financeiras estabelecidas em 1994 pelo CMN (Conselho Monetário Nacional) conforme resolução $\mathrm{n}^{\circ}$ 2.099. Atualmente, essas regras estão vigentes no país através da resolução $n^{\circ} 2.682$ de 1999, definida e controlada pelo Bacen (SILVA \& ROBLES JUNIOR, 2018).

\section{MÉTODO}

A metodologia qualitativa utilizada para este trabalho objetivou analisar os principais impactos financeiros (na conta de provisão para perdas estimadas para crédito de liquidação duvidosa) oriundos da mudança na metodologia prevista na IFRS 9 para mensuração da perda esperada de instituições financeiras que atuam no Brasil, e para fins de comparação foram utilizados as instituições Itaú, Bradesco e Santander.

\section{RESULTADOS E DISCUSSÃO}

De acordo com CMN (1999), a Resolução $n^{\circ} 2.682$ tem como objetivo expor os critérios das operações de crédito e regras para a constituição de provisão para créditos de liquidação duvidosa. As instituições financeiras autorizadas a funcionar pelo Bacen devem classificar as operações de crédito em níveis de risco de acordo com dias de atraso e 
informações internas da instituição, sendo eles: AA, A, B, C, D, E, F, G e H. Mensalmente, deve-se avaliar o nível de risco em função do atraso verificado no pagamento de parcela de principal ou de encargos, com revisão mensal, conforme Quadro 1.

Quadro 1 - Rating de acordo com a faixa de atraso

\begin{tabular}{|c|c|}
\hline Dia de atraso & Rating \\
\hline 15 a 30 & B \\
\hline 31 a 60 & C \\
\hline 61 a 90 & D \\
\hline 91 a 120 & E \\
\hline 121 a 150 & F \\
\hline 151 a 180 & G \\
\hline Acima de 180 & H \\
\hline
\end{tabular}

Fonte: Resolução 2.682 (CMN, 1999)

O conceito trabalhado neste normativo é a constituição da provisão através de perda esperada, pois é atribuído um valor de provisão para perda sem que o cliente tenha apresentado necessariamente algum indício de inadimplência (FONTENELE, 2013).

Além da classificação em função do atraso, a instituição financeira também deve considerar critérios consistentes e verificáveis, amparada por informações internas e externas, contemplando as seguintes informações.

Quadro 2 - Informações internas e externas para avaliação do risco das operações

\begin{tabular}{|c|c|}
\hline Informação & Tópicos \\
\hline \multirow{9}{*}{$\begin{array}{l}\text { Relacionada ao devedor e seus } \\
\text { garantidores }\end{array}$} & Situação econômico-financeira \\
\hline & Grau de endividamento \\
\hline & Capacidade de geração de resultados \\
\hline & Fluxo de caixa \\
\hline & Administração e qualidade de controles \\
\hline & Pontualidade e atrasos nos pagamentos \\
\hline & Contingências \\
\hline & Setor de atividade econômica \\
\hline & Limite de crédito \\
\hline \multirow{3}{*}{ Relacionada à operação } & Natureza e finalidade da transação \\
\hline & $\begin{array}{l}\text { Características das garantias, particularmente quanto à } \\
\text { suficiência e liquidez }\end{array}$ \\
\hline & Valor \\
\hline
\end{tabular}

Fonte: Resolução 2.682 (CMN, 1999) 
Os critérios listados no Quadro 2 devem ser revistos a cada seis meses, para operações de um mesmo cliente ou grupo econômico cujo montante seja superior a 5\% (cinco por cento) do patrimônio líquido ajustado, e uma vez a cada doze meses, em todas as situações.

Cada operação de crédito é avaliada e classificada segundo seu nível de risco e quando for observado mais de um rating para esta, por questão de conservadorismo, atribui-se a classificação que estiver mais próxima ao rating $\mathrm{H}$. Uma vez atribuído o nível de risco, determina-se o percentual de perda correspondente ao rating, como previsto na Resolução CMN 2.682/99. Esse percentual é aplicado no montante da operação para se obter a Provisão para Crédito de Liquidação Duvidosa (PCLD) (FONTENELE, 2013).

O BCB exige que a mensuração da PCLD seja feita com periodicidade mensal, através da aplicação de percentuais estabelecidos, não podendo estes inferiores aos percentuais mostrados no Quadro 3.

Quadro 3 - Percentual de provisão de acordo com o atraso

\begin{tabular}{|c|c|c|}
\hline Dias de atraso & Rating & \% Provisão \\
\hline 0 a 14 & $\mathrm{~A}$ & $0.5 \%$ \\
\hline 15 a 30 & $\mathrm{~B}$ & $1.0 \%$ \\
\hline 31 a 60 & $\mathrm{C}$ & $3.0 \%$ \\
\hline 61 a 90 & $\mathrm{D}$ & $10.0 \%$ \\
\hline 91 a 120 & $\mathrm{E}$ & $30.0 \%$ \\
\hline 121 a 150 & $\mathrm{~F}$ & $50.0 \%$ \\
\hline 151 a 180 & $\mathrm{G}$ & $70.0 \%$ \\
\hline Acima 180 & $\mathrm{H}$ & $100.0 \%$ \\
\hline
\end{tabular}

Fonte: Resolução 2.682 (CMN, 1999)

Vale destacar que para as operações com prazo a decorrer superior a 36 meses, admitese a contagem em dobro dos prazos. Por exemplo: contrato de crédito imobiliário com prazo remanescente igual a 10 anos (120 meses) apresenta contagem de prazo em dobro e, consequentemente, para ser classificado como rating $\mathrm{B}$, pode apresentar atraso máximo igual a 60 dias.

Resumidamente, de acordo com Fontenele (2013), a Resolução CMN 2.682/99 instituí o cálculo da provisão com base no conceito de perda esperada, devido ao fato de que a classificação de risco e, consequentemente, a atribuição do percentual de provisão são fundamentadas pela avaliação prévia da operação (anterior ao evento de deterioração da qualidade do crédito). Ou seja, toda operação de crédito tem um nível de risco atribuído ao cliente sem que o mesmo tenha incorrido em inadimplência.

De acordo com CMN (1999), a instituição não pode reconhecer receitas e encargos de qualquer natureza relacionados às operações de crédito com atraso igual ou superior a 60 (sessenta) dias, no pagamento de parcela de principal ou encargos.

No que se refere ao período de write-off (prejuízo), a Resolução institui que depois de decorridos 6 (seis) meses da classificação da operação em rating $\mathrm{H}$, esta deve ser classificada como prejuízo, ser transferida para conta de compensação e apresentar o correspondente débito em provisão. 


\subsection{IASB e a Norma IFRS 9}

O IASB (International Accounting Standards Board ou Comitê de Normas Internacionais de Contabilidade) tem como objetivo desenvolver, com base em princípios claramente articulados, um conjunto único de normas de contabilidade de alta qualidade, compreensíveis, exequíveis e aceitáveis globalmente. Trata-se de um órgão independente e emissor normas contábeis (CFC, 2020).

Diferentemente da Resolução 2.682, a norma IFRS 9 não estipula percentuais mínimos de provisão, mas sim diretrizes a serem adotadas para mensurar a provisão.

A norma IFRS 9, emitida pelo IASB, substitui a IAS 39 (IAS 39 Financial Instruments: Recognition and Measurement) e propõe um novo modelo de reconhecimento e mensuração para impairment de empréstimos e recebíveis que são como custo amortizado ou valor justo por meio de outros resultados abrangentes, denominado modelo de perdas esperadas de crédito ("expected credit losses" model), exemplificado na Figura 1 (PwC, 2014).

Figura 1 - Classificação e mensuração de ativos financeiros

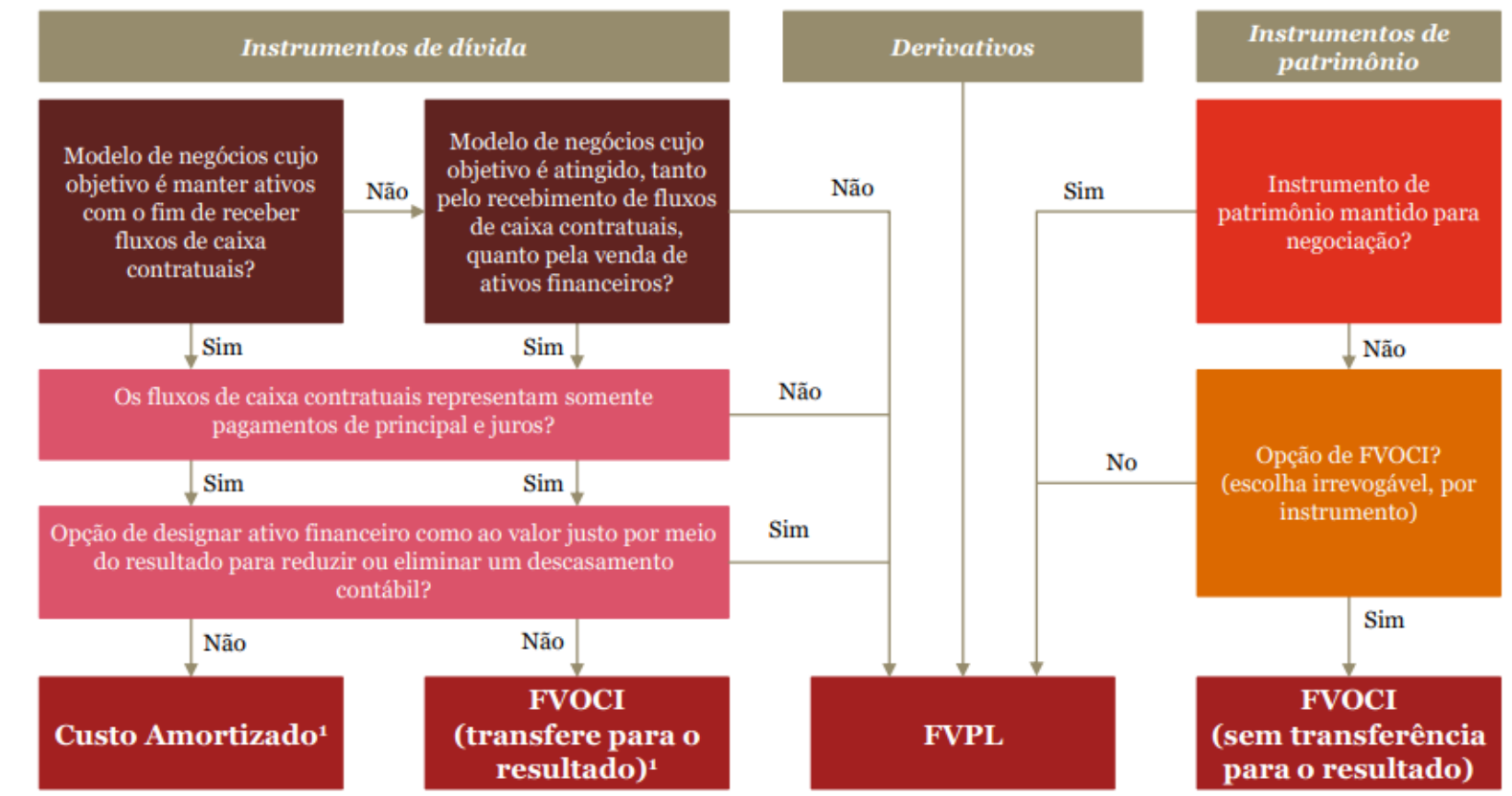

1 Requisitos de impairment se aplicam.

Fonte: PwC, 2014

De acordo com a norma IFRS 9, as perdas esperadas de crédito são calculadas através da dos seguintes steps:

a) Identificação de cenários onde o empréstimo entra em descumprimento (default);

b) Estimação do déficit de caixa que seria incorrido em cada cenário (caso o descumprimento ocorresse);

c) Multiplicação da perda pela probabilidade de descumprimento;

d) Soma dos resultados de todos esses possíveis eventos de default.

O cálculo da perda esperada do empréstimo deve ocorrer desde o momento de sua origem ou aquisição e deve levar em consideração a qualidade creditícia do mesmo, desde o 
reconhecimento inicial até a data de reporte (IASB, 2014). Uma vez feita a avaliação da qualidade creditícia do contrato, este é classificado em 3 estágios, conforme Figura 2.

Figura 2: Alteração na qualidade de crédito desde o reconhecimento inicial

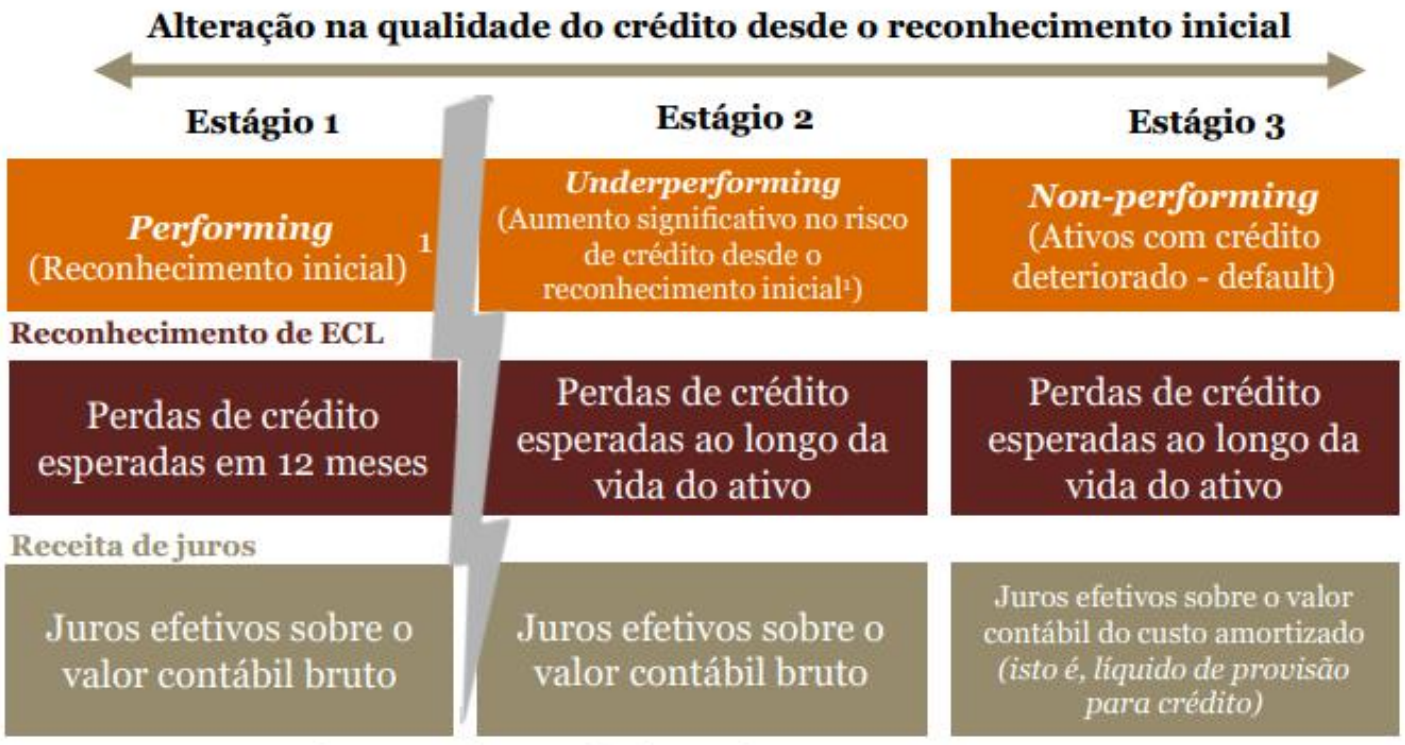

1. Exceto para ativos originados ou comprados com crédito deteriorado.

Fonte: PwC, 2014

Sendo assim, para cada estágio, a norma estabelece que a mensuração da perda esperada de crédito seja calculada para um horizonte temporal diferente. Contratos em estágio 1 tem a perda esperada calculada para um horizonte de 12 meses. Já os contratos classificados em estágio 2 ou 3 tem a perda esperada calculada para a vida do ativo ou lifetime (IASB, 2014).

Como requerimento mínimo, a norma IFRS 9 estipula o período de lifetime, para produtos não rotativos (parcelados), como o prazo máximo contratual, isto é, para se determinar a perda esperada de contratos em estágio 2 e 3, deve-se observar as parcelas remanescentes de cada um dos contratos. No entanto, para produtos rotativos (ex.: cartões de crédito, cheque especial, etc.) a norma abre uma exceção, pois estes possuem como vida contratual um prazo previamente estipulado, porém devido as suas características o prazo contratual estipulado pode não refletir o comportamento do ativo.

Dito isso, devido às características de tais instrumentos (rotativos), a instituição deve observar o lifetime do ativo através do período no qual o instrumento está exposto ao risco de crédito, isto é, quando este ativo demonstra uma deterioração, e as mesmas não seriam mitigadas por ações de risco de crédito. Neste caso, a IFRS 9 estabelece três considerações para determinação do lifetime, tais quais:

a) Período durante o qual a entidade foi exposta ao risco de crédito sobre instrumentos financeiros similares;

b) O período de tempo para a inadimplência ocorrer em instrumentos financeiros similares após um aumento risco de crédito; e,

c) As ações de gerenciamento de risco de crédito que a entidade espera adotar, quando o risco de crédito no instrumento financeiro tiver aumentado, como, por exemplo, a redução ou exclusão de limites não sacados. 
A norma IFRS 9 utiliza a metodologia de perda esperada (baseada em informações prospectivas) para mensurar a provisão para devedores duvidosos. A norma permite que a instituição classifique os ativos em 3 estágios, relacionados com a qualidade de crédito do ativo e não estabelece percentual de provisão.

Conforme o parágrafo B5.5.42, a IFRS 9 exige que a estimativa das perdas de crédito esperadas reflita um montante imparcial e ponderado por probabilidade, que é determinado pela avaliação de uma gama de resultados possíveis. Ou seja, a perda esperada deve considerar informações prospectivas em diferentes cenários macroeconômicos.

No que se refere ao reconhecimento de receitas de juros, conforme visto anteriormente na Figura 2, a norma estabelece que os estágios 1 e 2 tenham a receita de juros mensurada sob o valor contábil bruto e o estágio 3 tenha a receita de juros mensurada sob o valor contábil líquido:

No que se refere ao período de write-off (prejuízo), a norma IFRS 9 não delimita prazo de referência. Segundo o Parágrafo 5.4.4 da norma, o write-off de ativos financeiros deve ser considerado quando a entidade não possuir expectativas razoáveis para recuperar o ativo de forma integral ou parcial. O ponto no qual a entidade não possua mais tal expectativa depende do julgamento das situações e circunstâncias particulares de cada operação.

\subsection{Resolução 2.682 vs. IFRS 9}

Analisando o exposto nos tópicos anteriores, observa-se que a Resolução 2.682 e a norma IFRS 9 apresentam a instituição do cálculo da provisão baseada no conceito de perda esperada. A tabela a seguir apresenta um resumo comparativo dos principais pontos das duas regulamentações, ver Quadro 4.

Quadro 4 - Comparação entre a Resolução 2.682 e a norma IFRS 9

\begin{tabular}{|c|c|c|}
\hline Contexto & Resolução 2.682 & IFRS 9 \\
\hline $\begin{array}{c}\text { Mensuração da } \\
\text { provisão }\end{array}$ & $\begin{array}{c}\text { Atribuição de um percentual de } \\
\text { provisão vinculado ao nível de risco da } \\
\text { operação de crédito, relacionado a } \\
\text { quantidade de dias em atraso. }\end{array}$ & $\begin{array}{c}\text { Não há a atribuição de um percentual } \\
\text { de provisão mínimo ou de uma } \\
\text { metodologia específica para } \\
\text { mensuração de modelos de perda } \\
\text { esperada. }\end{array}$ \\
\hline $\begin{array}{c}\text { Horizonte de } \\
\text { mensuração }\end{array}$ & Não aplicável. & Lifetime (vida útil do contrato). \\
\hline $\begin{array}{c}\text { Variáveis } \\
\text { prospectivas }\end{array}$ & Não aplicável. & Aplicável. \\
\hline $\begin{array}{c}\text { Cenários } \\
\text { múltiplos }\end{array}$ & A0 dias. & $\begin{array}{c}\text { Vida inteível. } \\
\text { momento do write-off). }\end{array}$ \\
\hline $\begin{array}{c}\text { Stop-accrual } \\
\text { Write-off }\end{array}$ & $\begin{array}{c}\text { Rating } \mathrm{H}+6 \text { meses (360 dias ou 720 } \\
\text { dias para operações com prazo em } \\
\text { dobro). }\end{array}$ & $\begin{array}{c}\text { Prazo no qual a entidade não possui } \\
\text { expectativas razoáveis para recuperar o } \\
\text { ativo de forma integral ou parcial. }\end{array}$ \\
\hline
\end{tabular}

Fonte: desenvolvida pelos autores

Os seis principais princípios elencados na tabela anterior apresentam definições diferentes no que tange a Resolução 2.682 e a IFRS 9. 
Principais impactos na mensuração da Provisão para perdas estimadas com créditos de liquidação duvidosa (PECLD)

Para atingir o objetivo do trabalho foram analisadas as provisões calculadas em IFRS e BRGAAP (fechamento dezembro/2019), de 3 (três) instituições financeiras: Itaú, Bradesco e Santander. As informações foram coletadas através da análise das Demonstrações Contábeis das instituições supracitadas, disponibilizadas nos sites das instituições.

O comparativo entre as provisões de crédito de liquidação duvidosa foi realizado através do percentual de cobertura (razão entre o valor de provisão e a exposição total da carteira de crédito e a). Optou-se por utilizar essa métrica de comparação tendo em vista que a exposição total da carteira de crédito pode ser alterada no IFRS quando definido um período de write-off diferente do estabelecido em BRGAAP.

Para se chegar ao percentual de cobertura, foram coletados os dados nas demonstrações contábeis e estes foram tabulados. Após a tabulação dos dados, o valor total da provisão de crédito de liquidação duvidosa foi dividido pelo valor total da carteira (exposição).

Itaú

Sob a IFRS 9, o Banco Itaú Unibanco S.A., na nota explicativa 10 destacou a composição da carteira de operações de crédito e arrendamento mercantil, passível de impairment (Figura3).

Figura 3 - Carteira de Operações de Crédito e Arrendamento Mercantil Financeiro, segregadas por estágios (IFRS) - Itaú

\begin{tabular}{|c|c|c|c|c|c|c|c|c|}
\hline Estágio 1 & $\begin{array}{l}\text { Saldo em } \\
31 / 12 / 2018\end{array}$ & $\begin{array}{l}\text { Transferência } \\
\text { para Estágio } 2\end{array}$ & $\begin{array}{l}\text { Transferência } \\
\text { para Estágio } 3^{(7)}\end{array}$ & $\begin{array}{l}\text { Transferência do } \\
\text { Estágio } 2\end{array}$ & $\begin{array}{c}\text { Transferència do } \\
\text { Estágio } 3\end{array}$ & Write Off & $\begin{array}{l}\text { Aquisiçăo I } \\
\text { (Liquidaçăo) }\end{array}$ & $\begin{array}{c}\text { Saldo final em } \\
31 / 12 / 2019\end{array}$ \\
\hline Pessoas Fisicas & 177.488 & $(19.661)$ & $(2.009)$ & 8.680 & - & - & 35.409 & 199.907 \\
\hline Grandes Empresas & 90.716 & (854) & (90) & 886 & 13 & - & 5.152 & 95.823 \\
\hline Micro / Pequenas e Médias Empresas & 57.099 & (5.534) & (770) & 3.215 & 38 & - & 19.299 & 73.347 \\
\hline Unidades Externas América Latina & 134.323 & (12.022) & $(1.001)$ & 5.029 & 74 & - & 6.409 & 132.812 \\
\hline Total & 459.626 & $(38.071)$ & $(3.870)$ & 17.810 & 125 & - & 66.269 & 501.889 \\
\hline Estágio 2 & $\begin{array}{l}\text { Saldo em } \\
31 / 12 / 2018\end{array}$ & $\begin{array}{l}\text { Transferência } \\
\text { para Estágio } 1\end{array}$ & $\begin{array}{l}\text { Transferência } \\
\text { para Estágio } 3\end{array}$ & $\begin{array}{c}\text { Transferência do } \\
\text { Estágio } 1\end{array}$ & $\begin{array}{c}\text { Transferència do } \\
\text { Estágio } 3\end{array}$ & Write Off & $\begin{array}{c}\text { Aquisiçăo I } \\
\text { (Liquidaçăo) }\end{array}$ & $\begin{array}{c}\text { Saldo final em } \\
\text { 31/12/2019 }\end{array}$ \\
\hline Pessoas Fisicas & 17.029 & $(8.680)$ & $(7.579)$ & 19.661 & 977 & - & $(2.338)$ & 19.070 \\
\hline Grandes Empresas & 2.222 & (886) & (833) & 854 & 6 & - & (407) & 956 \\
\hline Micro / Pequenas e Médias Empresas & 5.875 & (3.215) & (1.759) & 5.534 & 477 & - & 268 & 7.180 \\
\hline Unidades Externas América Latina & 11.768 & $(5.029)$ & $(3.335)$ & 12.022 & 731 & - & $(1.443)$ & 14.714 \\
\hline Total & 36.894 & $(17.810)$ & $(13.506)$ & 38.071 & 2.191 & - & $(3.920)$ & 41.920 \\
\hline Estágio 3 & $\begin{array}{l}\text { Saldo em } \\
31 / 12 / 2018\end{array}$ & $\begin{array}{l}\text { Transferência } \\
\text { para Estágio } 1\end{array}$ & $\begin{array}{l}\text { Transferência } \\
\text { para Estágio } 2\end{array}$ & $\begin{array}{c}\text { Transferência do } \\
\text { Estágio } 1\end{array}$ & $\begin{array}{c}\text { Transferència do } \\
\text { Estágio } 2\end{array}$ & Write Off & $\begin{array}{c}\text { Aquisição I } \\
\text { (Liquidaçăo) }\end{array}$ & $\begin{array}{c}\text { Saldo final em } \\
\text { 31/12/2019 }\end{array}$ \\
\hline Pessoas Fisicas & 18.047 & - & $(977)$ & 2.009 & 7.579 & (9.710) & 4.565 & 21.513 \\
\hline Grandes Empresas & 9.705 & (13) & (6) & 90 & 833 & (884) & (1.202) & 8.523 \\
\hline Micro / Pequenas e Médias Empresas & 5.838 & (38) & (477) & 770 & 1.759 & (1.995) & (164) & 5.693 \\
\hline Unidades Externas América Latina & 5.981 & (74) & $(731)$ & 1.001 & 3.335 & $(1.710)$ & (1.549) & 6.253 \\
\hline Total & 39.571 & (125) & $(2.191)$ & 3.870 & 13.506 & (14.299) & 1.650 & 41.982 \\
\hline Consolidado dos 3 Estágios & & & & & $\begin{array}{c}\text { Saldo em } \\
31 / 12 / 2018\end{array}$ & Write Off & $\begin{array}{c}\text { Aquisiçăo / } \\
\text { (Liquidaçăo) }\end{array}$ & $\begin{array}{c}\text { Saldo final em } \\
31 / 12 / 2019\end{array}$ \\
\hline Pessoas Fisicas & & & & & 212.564 & $(9.710)$ & 37.636 & 240.490 \\
\hline Grandes Empresas & & & & & 102.643 & (884) & 3.543 & 105.302 \\
\hline Micro / Pequenas e Médias Empresas & & & & & 68.812 & (1.995) & 19.403 & 86.220 \\
\hline Unidades Externas América Latina & & & & & 152.072 & $(1.710)$ & 3.417 & 153.779 \\
\hline Total & & & & & 536.091 & (14.299) & 63.999 & 585.791 \\
\hline
\end{tabular}

Fonte: Itaú, 2019

O Banco Itaú possuía 585.791 milhões de reais em ativos financeiros que serão alocados nos três estágios de risco para mensuração da perda esperada de crédito. A perda 
esperada de crédito é calculada de forma individual, chegando ao resultado apresentado na Figura 4.

Figura 4 - Perda esperada de crédito para as Operações de Crédito e Arrendamento Mercantil Financeiro, segregadas por estágios (IFRS) - Itaú

\begin{tabular}{|c|c|c|c|c|c|c|c|c|}
\hline Estágio 1 & $\begin{array}{c}\text { Saldo em } \\
\text { 31/12/2018 }\end{array}$ & $\begin{array}{l}\text { Transferência } \\
\text { para Estágio } 2\end{array}$ & $\begin{array}{l}\text { Transferência } \\
\text { para Estágio } 3^{(1)}\end{array}$ & $\begin{array}{l}\text { Transferência do } \\
\text { Estágio } 2\end{array}$ & $\begin{array}{l}\text { Transferência do } \\
\text { Estágio } 3\end{array}$ & Write Off & $\begin{array}{c}\text { (Constituiçăo) / } \\
\text { Reversâo }\end{array}$ & $\begin{array}{l}\text { Saldo final em } \\
31 / 12 / 2019\end{array}$ \\
\hline Pessoas Fisicas & $(3.892)$ & 846 & 282 & $(264)$ & $\overline{-}$ & $\overline{-}$ & $(2.187)$ & $(5.215)$ \\
\hline Grandes Empresas & (531) & 59 & 2 & (170) & . & - & 123 & (517) \\
\hline Micro / Pequenas e Médias Empresas & $(1.112)$ & 225 & 71 & (136) & (10) & - & (119) & (1.081) \\
\hline Unidades Extermas América Latina & $(1.396)$ & 258 & 18 & $(160)$ & (40) & - & (33) & $(1.353)$ \\
\hline Total & $(6.931)$ & 1.388 & 373 & $(730)$ & $(50)$ & - & $(2.216)$ & $(8.166)$ \\
\hline Estágio 2 & $\begin{array}{c}\text { Saldo em } \\
\text { 31/12/2018 }\end{array}$ & $\begin{array}{l}\text { Transferência } \\
\text { para Estágio } 1\end{array}$ & $\begin{array}{l}\text { Transferência } \\
\text { para Estágio } 3\end{array}$ & $\begin{array}{l}\text { Transferência do } \\
\text { Estágio } 1\end{array}$ & $\begin{array}{l}\text { Transferência do } \\
\text { Estágio } 3\end{array}$ & Write Off & $\begin{array}{c}\text { (Constituiçăo) / } \\
\text { Reversâo }\end{array}$ & $\begin{array}{l}\text { Saldo final em } \\
\text { 31/12/2019 }\end{array}$ \\
\hline Pessoas Fisicas & $(2.116)$ & 264 & 3.117 & (846) & (155) & $\overline{-}$ & $(3.075)$ & $\overline{(2.811)}$ \\
\hline Grandes Empresas & (595) & 170 & 269 & (59) & - & - & 109 & (106) \\
\hline Micro / Pequenas e Médias Empresas & (557) & 136 & 490 & (225) & (143) & - & (576) & (875) \\
\hline Unidades Externas América Latina & (1.183) & 160 & 562 & (258) & $(268)$ & - & $(1.778)$ & $\frac{(2.765)}{(15.557)}$ \\
\hline Total & $(4.451)$ & 730 & 4.438 & $(1.388)$ & $(566)$ & 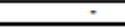 & $(5.320)$ & $\frac{(6.557)}{(1.57)}$ \\
\hline Estágio 3 & $\begin{array}{l}\text { Saldo em } \\
\text { 31/12/2018 }\end{array}$ & $\begin{array}{l}\text { Transferência } \\
\text { para Estágio } 1\end{array}$ & $\begin{array}{l}\text { Transferência } \\
\text { para Estágio } 2\end{array}$ & $\begin{array}{l}\text { Transferência do } \\
\text { Estágio } 1\end{array}$ & $\begin{array}{l}\text { Transferência do } \\
\text { Estágio } 2\end{array}$ & Write Off & $\begin{array}{c}\text { (Constituiçăo) / } \\
\text { Reversâo }\end{array}$ & $\begin{array}{l}\text { Saldo final em } \\
31 / 12 / 2019\end{array}$ \\
\hline Pessoas Fisicas & $(8.417)$ & - & 155 & (282) & (3.117) & 9.710 & $(9.476)$ & $\overline{(11.427)}$ \\
\hline Grandes Empresas & (8.241) & - & - & (2) & (269) & 884 & 1.260 & (6.368) \\
\hline Micro / Pequenas e Médias Empresas & $(2.863)$ & 10 & 143 & (71) & (490) & 1.995 & (1.211) & (2.487) \\
\hline Unidades Externas América Latina & $(2.606)$ & 40 & 268 & $(18)$ & $(562)$ & 1.710 & $(1.335)$ & $\frac{(2.503)}{152.797}$ \\
\hline Total & $(22.127)$ & 50 & 566 & (373) & $(4.438)$ & 14.299 & (10.762) & $(22.785)$ \\
\hline Consolidado dos 3 Estágios & & & & & $\begin{array}{c}\text { Saldo em } \\
\text { 31/12/2018 }\end{array}$ & Write Off & $\begin{array}{l}\text { (Constitulçăa) / } \\
\text { Revarsân (2) }\end{array}$ & $\begin{array}{l}\text { Saldo final em } \\
\text { 31/12/2019 }\end{array}$ \\
\hline Pessoas Fisicas & & & & & $(14.425)$ & 9.710 & $(14.738)$ & (19.453) \\
\hline Grandes Empresas & & & & & $(9.367)$ & 884 & 1.492 & (6.991) \\
\hline Micro / Pequenas e Médias Empresas & & & & & (4.532) & 1.995 & $(1.906)$ & (4.443) \\
\hline Unidades Externas América Latina & & & & & $(5.185)$ & 1.710 & $(3.146)$ & $\frac{(6.621)}{4}$ \\
\hline Total & & & & & $(33.509)$ & 14.299 & (18.298) & $(37.508)$ \\
\hline
\end{tabular}

Fonte: Itaú, 2019

Consolidando as informações extraídas da Demonstração Contábil, conclui-se que o Itaú apresenta um percentual de cobertura total de 6,4\%. Quando analisado de forma segmentada, o percentual de cobertura é crescente à medida que o risco de crédito aumenta, conforme exposto no Quadro 5.

Quadro 5 - Saldo, perda esperada e percentual de cobertura da carteira de crédito, segmentada por estágio (IFRS) - Itaú

\begin{tabular}{|c|c|c|c|}
\hline Estágio & Saldo (R\$ MM) & Perda Esperada (R\$ MM) & Percentual de cobertura \\
\hline 1 & 501.889 & $(8.166)$ & $1,63 \%$ \\
\hline 2 & 41.920 & $(6.557)$ & $15,64 \%$ \\
\hline 3 & 41.982 & $(22.785)$ & $54,27 \%$ \\
\hline Total & 585.791 & $(37.508)$ & $6,40 \%$ \\
\hline
\end{tabular}

Fonte: desenvolvida pelos autores 
Quando analisada a Demonstração Contábil em BRGAAP, na nota explicativa 3f, o Banco Itaú elucida como é mensurada a Provisão para Créditos de Liquidação Duvidosa (PCLD). Em linhas gerais, a PCLD é constituída a partir da análise dos riscos de realização dos créditos (em montante), analisando se esta será suficiente para cobertura de eventuais perdas atendidas às normas estabelecidas pela Resolução nº 2.682 (Figura 5).

Figura 5 - Carteira de Crédito, Arrendamento e Outros Créditos (BRGAAP) - Itaú

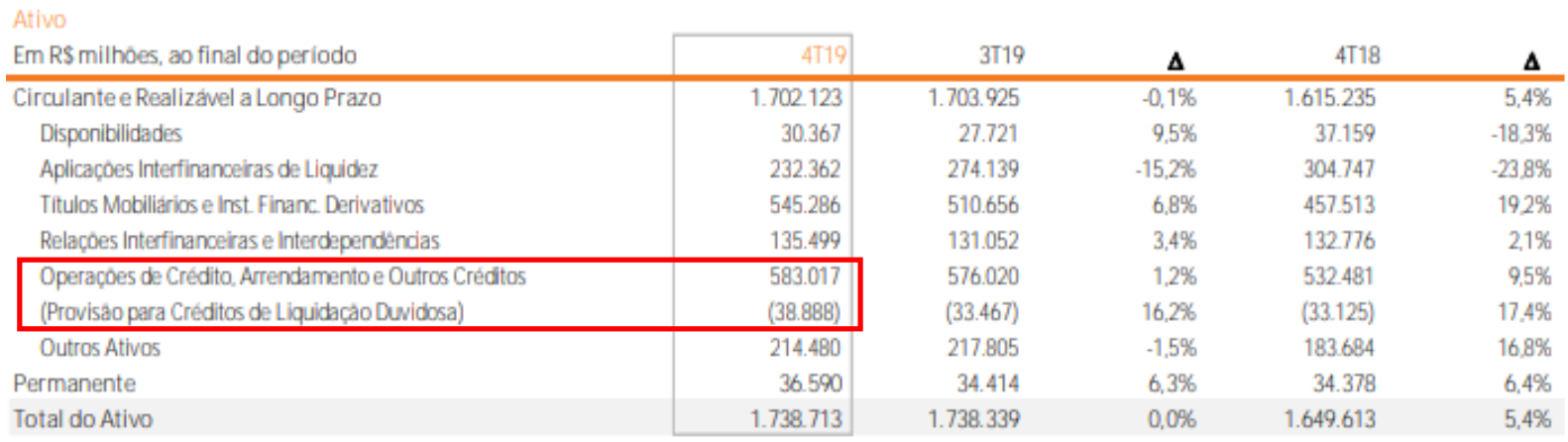

Fonte: Itaú, 2019

Nota-se que para BRGAAP, o percentual de cobertura da carteira é de 6,67\%. No entanto, esse valor inclui provisão complementar, conforme exposto na Figura 6.

Figura 6 - Saldo de PDD Mínimo e Complementar (BRGAAP) - Itaú

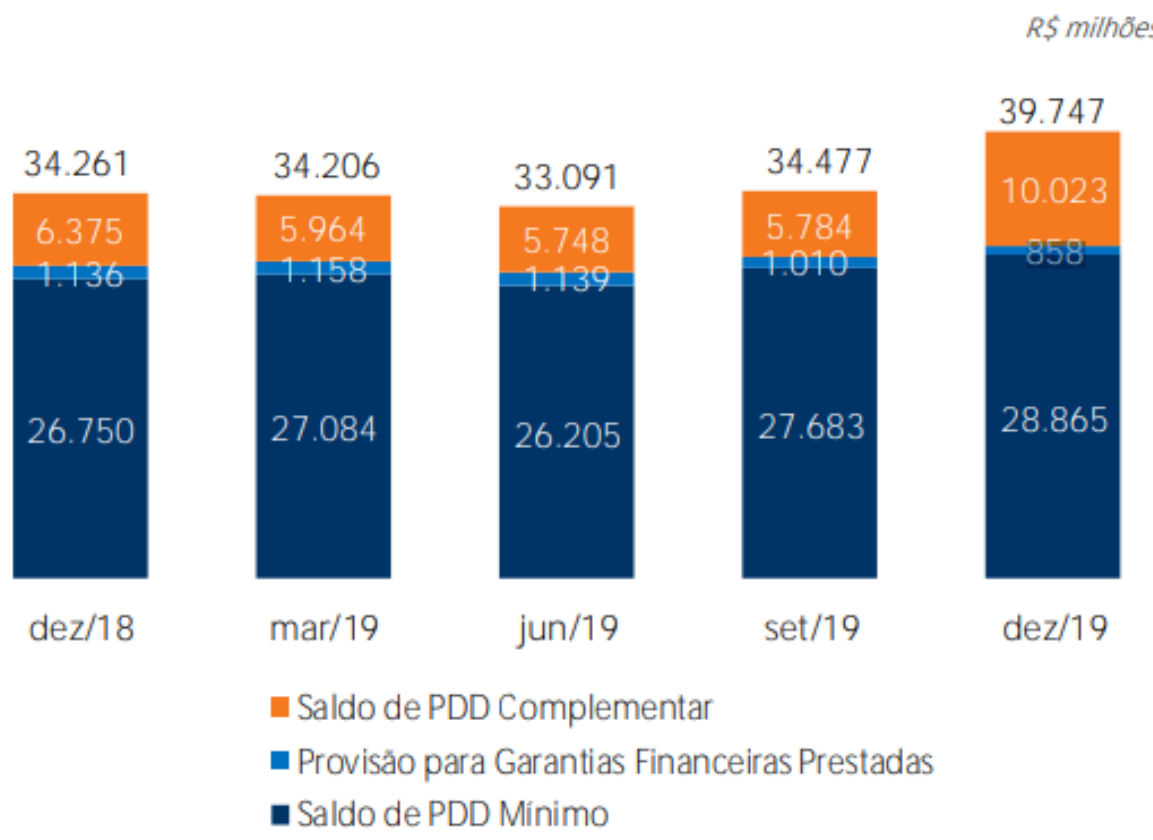

Fonte: Itaú, 2019

Ou seja, se a PCLD fosse mensurada sem considerar a provisão complementar, o banco estaria com um percentual de cobertura de $4,95 \%$. 


\subsubsection{Bradesco}

O Banco Bradesco S.A., na nota explicativa 10, demonstra a composição da carteira de operações de crédito e arrendamento mercantil, passível de impairment (Figura 7).

Figura 7 - Composição da Carteira de Operações de Crédito e Arrendamento Mercantil Financeiro IFRS - Fechamento Dez/19 - Bradesco

\begin{tabular}{|c|c|c|c|c|c|c|c|c|c|c|}
\hline \multirow[b]{2}{*}{ Estágio 1} & \multirow[b]{2}{*}{$\begin{array}{c}\text { Saldo em } \\
\text { 31.12.2018 }\end{array}$} & \multirow[b]{2}{*}{$\begin{array}{c}\text { Transferência } \\
\text { para Estágio } \\
\mathbf{2}\end{array}$} & \multirow[b]{2}{*}{$\begin{array}{c}\text { Transferência } \\
\text { para Estágio } \\
3\end{array}$} & \multirow[b]{2}{*}{$\begin{array}{l}\text { Oriundos do } \\
\text { Estágio } 2\end{array}$} & \multirow[b]{2}{*}{$\begin{array}{l}\text { Oriundos do } \\
\text { Estágio } 3\end{array}$} & \multirow[b]{2}{*}{ Amortizaçăo } & \multirow[b]{2}{*}{ Originados } & \multirow[b]{2}{*}{$\begin{array}{c}\text { Constituiçăol } \\
\text { (Reversâo) (1) }\end{array}$} & \multirow[b]{2}{*}{ (Write off) } & $R \$$ mil \\
\hline & & & & & & & & & & $\begin{array}{l}\text { Saldo em } \\
\text { 31.12.2019 }\end{array}$ \\
\hline Pessoa Júridica & 174.823 .333 & (3.530.473) & $(1.047 .643)$ & 1.740 .309 & 99.605 & (14.129.128) & 126.296 .922 & (91.016.561) & & 193.236 .364 \\
\hline Financiamentos & 87.491 .428 & $(2.665 .550)$ & (216.644) & 793.644 & 56.979 & $(6.599 .164)$ & 48.322 .133 & (35.550.497) & - & 91.632 .329 \\
\hline Empréstimos & 77.801 .046 & $(788.067)$ & (771.301) & 932.838 & 34.874 & (7.529.964) & 70.778 .365 & $(49.009 .228)$ & - & 91.448 .563 \\
\hline Operaçбes com limites & 9.530 .859 & (76.856) & (59.698) & 13.827 & 7.752 & & 7.196 .424 & $(6.456 .836)$ & - & 10.155.472 \\
\hline Pessoa Fisica & 164.711 .763 & (3.830.157) & $(2.331 .304)$ & 1.939 .655 & 323.117 & (15.271.291) & 126.773 .073 & (72.930.660) & - & 199.384.196 \\
\hline Financiamentos & 62.636 .298 & (2.196.138) & $(567.081)$ & 843.573 & 62.471 & $(8.742 .813)$ & 31.123 .133 & (10.161.286) & & 72.998 .157 \\
\hline Empréstimos & 69.241 .572 & (1.524.297) & (1.697.183) & 1.027 .710 & 154.480 & (6.528.478) & 62.155 .926 & (34.653.409) & - & 88.176 .321 \\
\hline Operaçбes com limites & 32.833 .893 & (109.722) & $(67.040)$ & 68.372 & 106.166 & & 33.494 .014 & $(28.115 .965)$ & - & 38.209 .718 \\
\hline Total & 339.535 .096 & $(7.360 .630)$ & (3.378.947) & 3.679.964 & 422.722 & (29.400.419) & 253.069 .995 & \begin{tabular}{l|l|}
$(163.947 .221)$ \\
\end{tabular} & - & 392.620 .560 \\
\hline
\end{tabular}

\begin{tabular}{|c|c|c|c|c|c|c|c|c|c|c|}
\hline \multirow[b]{2}{*}{ Estágio 2} & \multirow[b]{2}{*}{$\begin{array}{c}\text { Saldo em } \\
\text { 31.12.2018 }\end{array}$} & \multirow[b]{2}{*}{$\begin{array}{c}\text { Transferência } \\
\text { para Estágio } \\
1\end{array}$} & \multirow[b]{2}{*}{\begin{tabular}{|c} 
Transferência \\
para Estágio \\
3
\end{tabular}} & \multirow[b]{2}{*}{$\begin{array}{l}\text { Oriundos do } \\
\text { Estágio } 1\end{array}$} & \multirow[b]{2}{*}{$\begin{array}{l}\text { Oriundos do } \\
\text { Estágio } 3\end{array}$} & \multirow[b]{2}{*}{ Amortizaçăo } & \multirow[b]{2}{*}{ Originados } & \multirow[b]{2}{*}{$\begin{array}{l}\text { Constituiçăal } \\
\text { (Reversāo) (1) }\end{array}$} & \multirow[b]{2}{*}{ (Write off) } & R\$ mil \\
\hline & & & & & & & & & & $\begin{array}{l}\text { Saldo em } \\
\text { 31.12.2019 }\end{array}$ \\
\hline Pessoa Júridica & 21.750 .671 & (1.740.309) & (4.150.902) & 3.530 .473 & 604.824 & (1.537.738) & 5.702 .723 & (11.053.718) & - & 13.106 .024 \\
\hline Financiamentos & 11.855 .797 & $(793.644)$ & (3.637.599) & 2.665 .550 & 183.776 & $(640.153)$ & 768.132 & (4.669.507) & - & 5.732 .352 \\
\hline Empréstimos & 9.449 .412 & (932.838) & $(510.021)$ & 788.067 & 415.621 & (897.585) & 4.445 .528 & $(6.000 .032)$ & - & 6.758 .152 \\
\hline Operaç̧es com limites & 445.462 & (13.827) & (3.282) & 76.856 & 5.427 & & 489.063 & (384.179) & - & 615.520 \\
\hline Pessoa Fisica & 15.354.577 & (1.939.655) & (1.100.985) & 3.830 .157 & 622.122 & (1.616.061) & 11.754 .505 & $(7.309 .945)$ & - & 19.594 .715 \\
\hline Financiamentos & 4.130.401 & (843.573) & (292.952) & 2.196 .138 & 70.757 & (550.578) & 693.061 & (835.952) & - & 4.567 .302 \\
\hline Empréstimos & 9.122 .134 & (1.027.710) & (691.602) & 1.524.297 & 479.625 & (1.065.483) & 8.288 .437 & (4.610.119) & - & 12.019 .579 \\
\hline Operaçøes com limites & 2.102 .042 & $(68.372)$ & (116.431) & 109.722 & 71.740 & & 2.773 .007 & $(1.863 .874)$ & - & 3.007 .834 \\
\hline Total & 37.105 .248 & (3.679.964) & (5.251.887) & 7.360 .630 & 1.226 .946 & (3.153.799) & 17.457 .228 & (18.363.663) & - & 32.700 .739 \\
\hline
\end{tabular}

\begin{tabular}{|c|c|c|c|c|c|c|c|c|c|c|}
\hline \multirow[b]{2}{*}{ Estágio 3} & \multirow[b]{2}{*}{$\begin{array}{c}\text { Saldo em } \\
31.12 .2018\end{array}$} & \multirow[b]{2}{*}{$\begin{array}{c}\text { Transferência } \\
\text { para Estágio } \\
1\end{array}$} & \multirow[b]{2}{*}{$\begin{array}{c}\text { Transferência } \\
\text { para Estágio } \\
\mathbf{2}\end{array}$} & \multirow[b]{2}{*}{$\begin{array}{c}\text { Oriundos } \\
\text { do Estágio } \\
1\end{array}$} & \multirow[b]{2}{*}{\begin{tabular}{|} 
Oriundos \\
do Estágio \\
$\mathbf{2}$
\end{tabular}} & \multirow[b]{2}{*}{ Amortizaçăo } & \multirow[b]{2}{*}{ Originados } & \multirow[b]{2}{*}{\begin{tabular}{|c} 
Constituiçăol \\
(Reversăo) \\
(1)
\end{tabular}} & \multicolumn{2}{|r|}{ R\$ mil } \\
\hline & & & & & & & & & (Write off) & $\begin{array}{l}\text { Saldo em } \\
\text { 31.12.2019 }\end{array}$ \\
\hline Pessoa Júridica & 22.370 .956 & (99.605) & $\begin{array}{l}(604.824) \\
\end{array}$ & 1.047 .643 & 4.150 .902 & (552.471) & 4.249 .360 & (3.941.465) & (5.986.498) & 20.633 .998 \\
\hline Financiamentos & 6.325 .568 & (56.979) & (183.776) & 216.644 & 3.637 .599 & (237.542) & 422.843 & (1.756.639) & (1.594.018) & $\begin{array}{l}6.773 .700 \\
\end{array}$ \\
\hline Empréstimos & 15.363.975 & (34.874) & (415.621) & 771.301 & 510.021 & (314.929) & 3.175 .691 & (1.928.627) & (4.005.755) & 13.121.182 \\
\hline Operaçбes com limites & 681.413 & $(7.752)$ & $(5.427)$ & 59.698 & 3.282 & & 650.826 & (256.199) & (386.725) & 739.116 \\
\hline Pessoa Fisica & 12.481 .355 & (323.117) & (622.122) & 2.331 .304 & 1.100 .985 & (1.010.738) & 6.655.466 & 1.502 .563 & (10.678.618) & 11.437 .078 \\
\hline Financiamentos & 1.094.697 & $(62.471)$ & $(70.757)$ & 567.081 & 292.952 & (372.611) & 215.265 & (117.483) & (496.868) & 1.049 .805 \\
\hline Empréstimos & 5.604 .645 & (154.480) & (479.625) & 1.697 .183 & 691.602 & (638.127) & 2.679 .383 & 1.146.472 & $(5.315 .534)$ & 5.231 .519 \\
\hline Operaçбes com limites & 5.782 .013 & (106.166) & (71.740) & 67.040 & 116.431 & & 3.760 .818 & 473.574 & $(4.866 .216)$ & 5.155 .754 \\
\hline Total & 34.852.311 & $(422.722)$ & (1.226.946) & 3.378.947 & 5.251 .887 & (1.563.209) & 10.904.826 & (2.438.902) & \begin{tabular}{|l|} 
(16.665.116) \\
\end{tabular} & \begin{tabular}{|l|}
32.071 .076 \\
\end{tabular} \\
\hline
\end{tabular}

\begin{tabular}{|c|c|c|c|c|c|c|}
\hline \multirow[b]{2}{*}{ Consolidado - 3 estágios } & \multirow[b]{2}{*}{$\begin{array}{c}\text { Saldo em } \\
\text { 31.12.2018 }\end{array}$} & \multirow[b]{2}{*}{ Amortização } & \multirow[b]{2}{*}{ Originados } & \multirow[b]{2}{*}{$\begin{array}{l}\text { Constituiçăal } \\
\text { (Reversâo) (1) }\end{array}$} & \multirow[b]{2}{*}{ (Write off) } & R\$ mil \\
\hline & & & & & & $\begin{array}{c}\text { Saldo em } \\
\text { 31.12.2019 }\end{array}$ \\
\hline Pessoa Jurídica & 218.944 .960 & (16.219.337) & 136.249 .005 & (106.011.744) & (5.986.498) & 226.976 .386 \\
\hline Financiamentos & 105.672 .793 & $(7.476 .859)$ & 49.513 .108 & $(41.976 .643)$ & (1.594.018) & 104.138.381 \\
\hline Empréstimos & 102.614 .433 & (8.742.478) & 78.399 .584 & $(56.937 .887)$ & (4.005.755) & 111.327.897 \\
\hline Operaçбes com limites & 10.657 .734 & & 8.336 .313 & $(7.097 .214)$ & (386.725) & 11.510 .108 \\
\hline Pessoa Fisica & 192.547.695 & (17.898.090) & 145.183.044 & (78.738.042) & (10.678.618) & 230.415.989 \\
\hline Financiamentos & 67.861 .396 & $(9.666 .002)$ & 32.031 .459 & (11.114.721) & (496.868) & 78.615 .264 \\
\hline Empréstimos & 83.968 .351 & (8.232.088) & 73.123 .746 & (38.117.056) & $(5.315 .534)$ & 105.427.419 \\
\hline Operaçбos com limites & 40.717 .948 & & 40.027 .839 & (29.506.265) & $(4.866 .216)$ & 46.373 .306 \\
\hline Total & 411.492 .655 & (34.117.427) & 281.432 .049 & (184.749.786) & (16.665.116) & 457.392 .375 \\
\hline
\end{tabular}

Fonte: Bradesco, 2019

Consolidando as informações extraídas da Demonstração Contábil, conclui-se que o Bradesco apresenta um percentual de cobertura total de 8,34\%. Quando analisado de forma 
segmentada, o percentual de cobertura é crescente à medida que o risco de crédito aumenta, conforme exposto no Quadro 6.

Quadro 6 - Saldo, perda esperada e percentual de cobertura da carteira de crédito, segmentada por estágio (IFRS) - Bradesco.

\begin{tabular}{|c|c|c|c|}
\hline Estágio & Saldo (R\$ MM) & Perda Esperada (R\$ MM) & Percentual de cobertura \\
\hline 1 & 392.621 & $(13.067)$ & $3,33 \%$ \\
\hline 2 & 32.701 & $(4.635)$ & $14,17 \%$ \\
\hline 3 & 32.071 & $(20.450)$ & $63,77 \%$ \\
\hline Total & 457.392 & $(38.152)$ & $8,34 \%$ \\
\hline
\end{tabular}

Fonte: desenvolvida pelos autores

Quando analisada a Demonstração Contábil em BRGAAP, nas notas explicativas $3 \mathrm{~g}$ e 9, o Banco Bradesco explicita como é mensurada a Provisão para Créditos de Liquidação Duvidosa (PECLD). Em linhas gerais, a PECLD é constituída a partir da classificação das operações de crédito, em nove níveis de risco, levando em consideração fatores e premissas dos clientes e das operações, tais como atraso, situação econômico-financeira, grau de endividamento, setor de atividade econômica, características das garantias e demais fatores e premissas estabelecidas na Resolução CMN n ${ }^{\circ}$ 2.682/99, sendo "AA" o risco mínimo e " $\mathrm{H}$ " o risco máximo.

Inicialmente, é mensurada a PECLD Mínima através da atribuição dos percentuais de perda instituídos pela referida Resolução a cada nível de risco. Posteriormente, é mensurada a PECLD Complementar através de estimativas baseadas em estudos internos (provisões específica e excedente), ver Figura 8.

Figura 8 - Composição das operações de crédito e da provisão para créditos de liquidação duvidosa - Bradesco

\begin{tabular}{|c|c|c|c|c|c|c|c|c|}
\hline \multirow{4}{*}{ Nivel de risco } & \multirow{2}{*}{\multicolumn{8}{|c|}{ Em 31 de dezembro - R\$ mil }} \\
\hline & & & & & & & & \\
\hline & \multicolumn{3}{|c|}{ Curso anormal } & \multirow[b]{2}{*}{ Curso normal } & \multirow[b]{2}{*}{ Total } & \multirow[b]{2}{*}{$\%(1)$} & \multirow{2}{*}{$\begin{array}{l}\% \text { Acumulado em } \\
2019 \text { (2) }\end{array}$} & \multirow{2}{*}{$\begin{array}{l}\text { \% Acumulado em } \\
2018 \text { (2) }\end{array}$} \\
\hline & Vencidas & Vincendas & $\begin{array}{l}\text { Total - curso } \\
\text { anormal }\end{array}$ & & & & & \\
\hline AA & - & & & 142.004 .361 & 142.004 .361 & 31,3 & 31,3 & 32,6 \\
\hline A & & & & 170.724 .534 & 170.724 .534 & 37,7 & 69,0 & 69,0 \\
\hline B & 457.549 & 2.656 .707 & 3.114 .256 & 46.248 .675 & 49.362 .931 & 10,9 & 79,9 & 78,5 \\
\hline $\mathrm{c}$ & 999.061 & 2.750 .416 & 3.749 .477 & 43.965 .678 & 47.715 .155 & 10,5 & 90,4 & 89,5 \\
\hline Subtotal & 1.456 .610 & 5.407 .123 & 6.863 .733 & 402.943.248 & 409.806 .981 & 90,4 & & \\
\hline D & 905.224 & 2.123 .485 & 3.028 .709 & 4.947 .633 & 7.976 .342 & $\frac{0,7}{1,8}$ & 92,2 & 91,8 \\
\hline $\mathrm{E}$ & 956.834 & 1.608 .515 & 2.565 .349 & 5.576 .936 & 8.142 .285 & 1,8 & 94,0 & 93,3 \\
\hline $\mathrm{F}$ & 757.881 & 924.571 & 1.682 .452 & 2.455 .669 & 4.138.121 & 0,9 & 94,9 & 95,0 \\
\hline G & 810.607 & 1.168.378 & 1.978 .985 & 2.054 .265 & 4.033 .250 & 0,9 & 95,8 & 95,8 \\
\hline H & 6.555 .145 & 4.386 .617 & 10.941 .762 & 7.902 .933 & 18.844 .695 & 4,2 & 100,0 & 100,0 \\
\hline Subtotal & 9.985 .691 & 10.211 .566 & 20.197 .257 & 22.937 .436 & 43.134.693 & 9,6 & & \\
\hline Total geral em 2019 & 11.442.301 & 15.618 .689 & 27.060 .990 & 425.880 .684 & 452.941 .674 & 100,0 & & \\
\hline$\%$ & 2,5 & 3,4 & 5,9 & 94,1 & 100,0 & & & \\
\hline Total geral em 2018 & 10.934 .544 & 13.732 .960 & 24.667 .504 & 382.150 .316 & 406.817 .820 & & & \\
\hline$\%$ & 2,7 & 3,4 & 6,1 & 93,9 & 100,0 & & & \\
\hline
\end{tabular}




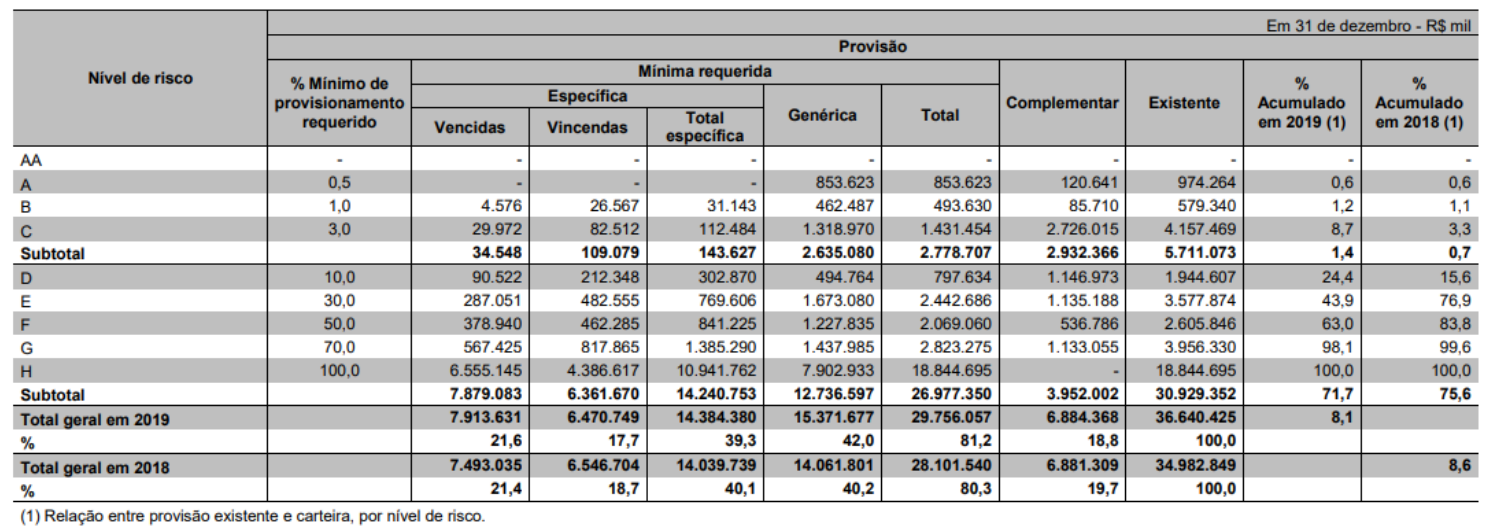

Fonte: Bradesco, 2019

Nota-se que para BRGAAP, o percentual de cobertura da carteira é de 8,09\% (esse valor inclui provisão complementar). Quando analisada a PECLD sem considerar a provisão complementar, o banco estaria com um percentual de cobertura de $6,57 \%$.

\subsubsection{Santander}

O Banco Santander S.A., na nota explicativa 9, demonstra a composição da carteira de operações de crédito e arrendamento mercantil, passível de impairment (Figura 9).

Figura 9 - Composição da Carteira de Operações de Crédito e Arrendamento Mercantil Financeiro IFRS - Fechamento Dez/19 - Santander

\begin{tabular}{|c|c|c|c|}
\hline Em milhares de Reais & 2019 & 2018 & 2017 \\
\hline \multicolumn{4}{|l|}{ Classificaçăo: } \\
\hline Ativos Financeiros Mensurados ao Valor Justo no Resultado & - & - & - \\
\hline $\begin{array}{l}\text { Ativos Financeiros năo Destinados a Negociaçăo Mensurados Obrigatoriamente a Valor } \\
\text { Justo no Resultado }\end{array}$ & - & 619.180 & - \\
\hline Empréstimos e Receblveis & \multicolumn{3}{|c|}{$-272.420 .157$} \\
\hline Ativos Financeiros mensurados ao custo Amortizado & 326.699 .480 & 301.072 .207 & - \\
\hline \multicolumn{4}{|l|}{ Sendo: } \\
\hline Empréstimos e adiantamentos a clientes ao custo amortizado & 347.256 .660 & 321.314 .010 & 287.829 .213 \\
\hline Provisăo para perdas por não recuperação ("impairment") & $(20.557 .180)$ & $(20.241 .803)$ & $(15.409 .056)$ \\
\hline Empréstimos e adiantamentos a clientes, líquidos & 326.699 .480 & 301.691 .387 & 272.420 .157 \\
\hline Empréstimos e adiantamentos a clientes, brutos & 347.256 .660 & 321.933 .190 & 287.829 .213 \\
\hline Em milhares de Reais & 2019 & 2018 & 2017 \\
\hline \multicolumn{4}{|l|}{ Tipo: } \\
\hline Operaçöes de crédito ${ }^{(1)}$ & 329.910 .319 & 308.364 .517 & 272.561 .017 \\
\hline Operaçōes de arrendamento mercantil & 2.111 .842 & 1.836 .504 & 1.888 .444 \\
\hline Operaçøes compromissadas & 10.500 & 509.147 & 403.415 \\
\hline Outros recebiveis ${ }^{(2)}$ & 15.223 .999 & 11.223 .022 & 12.976 .337 \\
\hline Total & 347.256 .660 & 321.933 .190 & 287.829 .213 \\
\hline
\end{tabular}

Fonte: Santander, 2019

Consolidando as informações extraídas da Demonstração Contábil, conclui-se que o Santander apresenta um percentual de cobertura total de 5,92\%.

Quando analisada a Demonstração Contábil em BRGAAP, nas notas explicativas 3i, Banco Santander explicita como é mensurada a Provisão para Créditos de Liquidação Duvidosa (PECLD). A instituição define como carteira de crédito as operações de crédito,
Refas - ISSN 2359-182X
v.8, n.1
Outubro de 2021 
operações de arrendamento mercantil, adiantamentos sobre contratos de câmbio e outros créditos com características de concessão de crédito. Estas operações, conforme estabelecido pela Resolução CMN no 2.682/1999, apresentam provisões fundamentadas nas análises das operações de crédito em aberto (vencidas e vincendas), na experiência passada, expectativas futuras e riscos específicos das carteiras e na política de avaliação de risco da Administração na constituição das provisões (SANTANDER, 2019).

Na nota explicativa 8.e, a Instituição demonstra como a carteira de créditos é composta e qual o valor de provisão a ela atribuída (Figura 10).

Figura 10 - Composição da carteira de créditos e da provisão para créditos de liquidação duvidosa Santander

\begin{tabular}{|c|c|c|c|c|c|c|c|}
\hline \multirow[b]{2}{*}{$\begin{array}{c}\text { Nivel de } \\
\text { Risco }\end{array}$} & \multirow[b]{2}{*}{$\begin{array}{r}\% \text { Provisăo } \\
\text { Minima } \\
\text { Requerida }\end{array}$} & \multicolumn{5}{|c|}{ Carteira de Créditos } & \multirow{2}{*}{$\begin{array}{r}\text { Banco } \\
31 / 12 / 2019 \\
\text { Provisăo } \\
\\
\text { Total }\end{array}$} \\
\hline & & $\begin{array}{l}\text { Curso } \\
\text { Normal }\end{array}$ & $\begin{array}{r}\text { Curso } \\
\text { Anormal (1) }\end{array}$ & Total (3) & Requerida & Adicional (2) & \\
\hline AA & - & 121.753 .569 & - & 121.753 .569 & - & - & 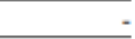 \\
\hline $\mathrm{A}$ & $0,5 \%$ & 77.795 .391 & - & 77.795 .391 & 388.977 & - & 388.977 \\
\hline B & $1 \%$ & 23.816.916 & 2.120 .722 & 25.937 .638 & 259.376 & 17 & 259.393 \\
\hline $\mathrm{C}$ & $3 \%$ & 19.823 .183 & 1.966 .467 & 21.789 .651 & 653.690 & 1.665 & 655.355 \\
\hline D & $10 \%$ & 7.926 .118 & 2.088 .778 & 10.014 .896 & 1.001 .490 & 1.547 .683 & 2.549 .173 \\
\hline $\mathrm{E}$ & $30 \%$ & 2.266 .765 & 2.323.208 & 4.589 .973 & 1.376 .992 & 659.874 & 2.036 .866 \\
\hline$F$ & $50 \%$ & 1.769 .671 & 1.475 .413 & 3.245 .084 & 1.622 .542 & 447.224 & 2.069 .766 \\
\hline G & $70 \%$ & 1.450 .313 & 1.225 .377 & 2.675 .689 & 1.872 .983 & 418.317 & 2.291 .300 \\
\hline$\underline{\mathrm{H}}$ & $100 \%$ & 2.734 .332 & 5.676 .805 & 8.411.137 & 8.411 .137 & - & 8.411 .137 \\
\hline Total & & 259.336.258 & 16.876 .770 & 276.213 .028 & 15.587.187 & 3.074 .780 & 18.661 .967 \\
\hline
\end{tabular}

Fonte: Santander, 2019

Nota-se que para BRGAAP, o percentual de cobertura da carteira é de 6,76\% (esse valor inclui provisão complementar). Quando analisada a PCLD sem considerar a provisão complementar, o banco estaria com um percentual de cobertura de 5,64\%.

A partir das informações coletadas e expostas no capítulo anterior, observou-se que todas as instituições financeiras analisadas apresentaram exposição de crédito superior nas demonstrações em IFRS. Com isso, podemos concluir que o prazo para write-off IFRS é superior ao instituído pelo Bacen (Quadro 7).

Quadro 7 - Saldo, perda esperada e percentual de cobertura das instituições analisada

\begin{tabular}{|c|c|c|c|c|}
\hline Instituição & Publicação & Saldo (R\$ MM) & Perda Esperada (R\$ MM) & \% cobertura \\
\hline \multirow{2}{*}{ Itaú } & IFRS & 585.791 & 37.508 & $6,40 \%$ \\
\cline { 2 - 5 } & BRGAAP & 583.017 & 38.888 & $6,67 \%$ \\
\hline \multirow{2}{*}{ Bradesco } & IFRS & 457.392 & 38.152 & $8,34 \%$ \\
\cline { 2 - 5 } & BRGAAP & 452.942 & 36.640 & $8,09 \%$ \\
\hline \multirow{2}{*}{ Santander } & IFRS & 347.257 & 20.557 & $5,92 \%$ \\
\cline { 2 - 5 } & BRGAAP & 276.213 & 18.662 & $6,76 \%$ \\
\hline
\end{tabular}

Fonte: desenvolvida pelos autores 
Quando analisada a perda esperada dessas instituições, nota-se que o Itaú e o Santander apresentam percentual de cobertura da provisão em BRGAAP superior ao percentual de cobertura da provisão em BRGAAP. No entanto, vale destacar que o valor exposto na tabela anterior se refere à provisão mínimo Bacen (requerida pela Resolução 2.682) adicionada da provisão complementar.

Para analisar o percentual de cobertura da provisão BRGAAP de forma segregada (provisão mínima e complementar), foi desenvolvida a tabela a seguir, onde é possível observar os valores de provisão e percentual de cobertura de cada instituição para a publicação IFRS e BRGAAP (mínima e complementar), ver Quadro 8.

Quadro 8 - Saldo, perda esperada e percentual de cobertura das instituições analisada

\begin{tabular}{|c|c|c|c|}
\hline Instituição & Publicação & Perda Esperada (R\$ MM) & \% cobertura \\
\hline \multirow{3}{*}{ Itaú } & IFRS & 37.508 & $6,40 \%$ \\
\cline { 2 - 4 } & BRGAAP - PECLD mínima & 28.865 & $4,95 \%$ \\
\cline { 2 - 4 } & BRGAAP - PECLD Compl. & 10.023 & $1,72 \%$ \\
\hline \multirow{3}{*}{ Bradesco } & IFRS & 38.152 & $8,34 \%$ \\
\cline { 2 - 4 } & BRGAAP - PCLD mínima & 29.756 & $6,57 \%$ \\
\cline { 2 - 4 } & BRGAAP - PECLD Compl. & 6.884 & $1,52 \%$ \\
\hline \multirow{3}{*}{ Santander } & IFRS & 20.557 & $5,92 \%$ \\
\cline { 2 - 4 } & BRGAAP - PECLD mínima & 15.587 & $1,11 \%$ \\
\cline { 2 - 4 } & BRGAAP - PECLD Compl. & 3.075 & $5,64 \%$ \\
\hline
\end{tabular}

Fonte: desenvolvida pelos autores

Assim, quando comparada a provisão mínimo Bacen (Resolução 2.682) com a provisão IFRS é possível observar que todas as instituições financeiras analisadas apresentaram provisão de crédito de liquidação duvidosa na publicação IFRS superior a publicação segundo o BRGAAP (PECLD mínima), ver Gráfico 1.

Gráfico 1 - Exposição e provisão para IFRS e BRGAAP

\section{Exposição e Provisão - Fechamento Dez/19}

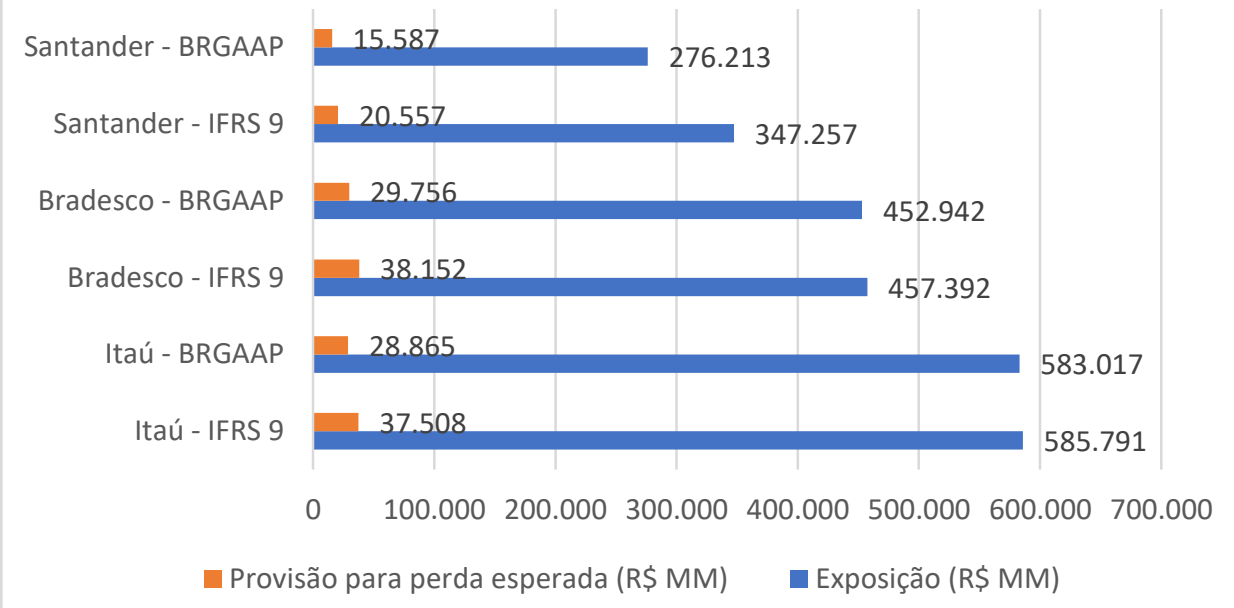

Fonte: desenvolvido pelos autores 
A expectativa era de que as provisões apresentadas segundo as normas internacionais (IFRS) fossem superiores a publicação segundo a Resolução CMN 2.682/99, pois a norma IFRS 9 exige que a provisão seja mensurada para a vida inteira do contrato quando este apresentar sinais de deterioração e que sejam consideradas informações prospectivas e cenários múltiplos.

Outro fator que pode corroborar com a expectativa supracitada, refere-se à definição do writeoff. Como já mencionado, as três instituições possuem exposição maior em IFRS, o que pode ser um forte indício de que o prazo de write-off IFRS seja superior ao instituído pelo Bacen.

\section{CONSIDERAÇÕES FINAIS}

Ao analisar das Demonstrações Contábeis, observou-se que as instituições financeiras não publicam a metodologia de apuração da PECLD segundo as normas internacionais, apenas algumas premissas adotadas. Sendo assim, não é possível avaliar profundamente as variáveis envolvidas no processo de determinação dos parâmetros de risco que compõem o cálculo da PECLD e que justifiquem o valor a maior na publicação de IFRS.

Como pesquisas futuras, sugere-se um aprofundamento em relação à incorporação das variáveis prospectivas nos parâmetros de risco envolvidos no cálculo da PECLD no IFRS, como objetivo de concluir se a provisão IFRS é superior à BRGAAP devido aos impactos das variáveis prospectivas e dos cenários macroeconômicos.

\section{REFERÊNCIAS}

BANCO CENTRAL DO BRASIL. Banco Central do Brasil: fique por dentro / Banco Central do Brasil. $4^{a}$ edição. Brasília. 2008. Disponível em:

<https://www.bcb.gov.br/htms/sobre/bcuniversidade/cartilhaBancoCentral.pdf>. Acesso em: 27 abr. 2021.

BRADESCO. Demonstrações Contábeis Consolidadas de acordo com as Normas internacionais de relatório financeiro (IFRS) emitidas pelo "International Accounting Standards Board IASB”. 2019. Disponível em:

<https://www.bradescori.com.br/siteBradescoRI/Uploads/Arquivos/Relatorios/676/676_1_IF RS\%20Portugu\%c3\%aas\%20V0\%2006.03\%20-\%20Final.pdf >. Acesso em: 08 mai. 2020.

BRADESCO. Relatório de Análise Econômica e Financeira. $4^{0}$ trimestre 2019. Disponível em:

<https://www.bradescori.com.br/siteBradescoRI/Uploads/Arquivos/Relatorios/652/652_1_Bo ok_Port.pdf $>$. Acesso em: 15 mai. 2021.

BRASIL. Lei no 4.595 de 31 de dezembro de 1964. Dispõe sobre a Política e as Instituições Monetárias, Bancárias e Creditícias, cria o Conselho Monetário Nacional e dá outras providências. Disponível em:

<http://www.planalto.gov.br/ccivil_03/leis/14595.htm\#: :text=LEI\%20N\%C2\%BA\%204.595 \%2C\%20DE\%2031\%20DE\%20DEZEMBRO\%20DE\%201964\&text=Disp\%C3\%B5e\%20so 
bre $\% 20$ a $\% 20$ Pol $\%$ C3\%ADtica\%20e,Nacional\%20e\%20d\%C3\%A1\%20outras\%20provid\%C 3\%AAncias. >. Acesso em: 04 jun. 2021.

CONSELHO MONETÁRIO NACIONAL (CMN). Resolução n 2.099, de 26 de agosto de 1994. Aprova regulamentos que dispõem sobre as condições relativamente ao acesso ao Sistema Financeiro Nacional. Disponível em:

https://www.bcb.gov.br/pre/normativos/res/1994/pdf/res_2099_v1_O.pdf>. Acesso em: 15 out. 2020.

CONSELHO MONETÁRIO NACIONAL (CMN). Resolução n 2.682, de 21 de dezembro de 1999. Dispõe sobre critérios de classificação das operações de crédito e regras para constituição de provisão para créditos de liquidação duvidosa. Disponível em: <http://www.bcb.gov.br/pre/normativos/res/1999/pdf/res_2682_v2_L.pdf >. Acesso em: 15 out. 2020.

CONSELHO FEDERAL DE CONTABILIDADE (CFC). Assuntos Internacionais. Disponível em: <https://cfc.org.br/tecnica/assuntos-internacionais/>. Acesso em: 30 mai. 2021.

FONTENELE, Caroline Pacheco. Análise do impacto causado na provisão de crédito de liquidação duvidosa devido as normas internacionais de contabilidade (IFRS). Brasília, 2013. Disponível em: <https://bdm.unb.br/handle/10483/11829>. Acesso em: 09 out. 2019

PWC. In depth: A look at current financial reporting issues. IFRS 9: Expected Credit Losses. 2014. Disponível em: <https://www.pwc.com/gx/en/audit-

services/ifrs/publications/ifrs-9/ifrs-in-depth-expected-credit-losses.pdf $>$. Acesso em: 27 set. 2019.

PWC. In depth: A look at current financial reporting issues. IFRS 9: Classification and measurement. 2014. Disponível em: <https://www.pwc.com.au/assurance/ifrs/assets/ifrs9classification-and-measurement-pwc-indepth2014-05.pdf>. Acesso em: 27 set. 2019.

SILVA, K. O.; ROBLES JUNIOR, A. Provisão para créditos de liquidação duvidosa (PCLD) calculada conforme as normas do BACEN e IFRS: comparação. 2018. Disponível em: 〈https://revistas.pucsp.br/CAFI/article/view/36949/25173>. Acesso em: 15 out. 2019.

IASB. INTERNATIONAL ACCOUNTING STANDARDS BOARD. IFRS 9 Financial Instruments. Julho, 2014.

ITAÚ. Demonstrações Contábeis Completas em IFRS. 31 de dezembro de 2019.

Disponível em: <https://www.itau.com.br/relacoes-com-

investidores/Download.aspx?Arquivo=31GRhXOaScijiUMSodxgaw==>. Acesso em: 20 abr. 2020.

ITAÚ. Análise Gerencial da Operação e Demonstrações Contábeis Completas. 4T19.

Disponível em: https://www.itau.com.br/relacoes-com-

investidores/Download.aspx?Arquivo=h6WQ5bq1WRA7sUz54cF52w==. Acesso em: $20 \mathrm{abr}$. 2020.

SANTANDER. Demonstrações Financeiras Consolidadas Preparadas de Acordo com as Normas Internacionais de Relatórios Financeiros - IFRS. 31 de dezembro de 2019.

Disponível em: <https://cms.santander.com.br/sites/WRI/documentos/url-df-ifrs-4t19/20-0228_015529_df\%20ifrs\%204t19.pdf>. Acesso em: 05 mai. 2020.

SANTANDER. Demonstrações Financeiras Individuais e Consolidadas Preparadas de Acordo com Práticas Contábeis Adotadas no Brasil Aplicáveis às Instituições Autorizadas a Funcionar pelo Banco Central do Brasil. 31 de dezembro de 2019.

Refas - ISSN 2359-182X v.8, n.1 Outubro de 2021


Disponível em: <https://cms.santander.com.br/sites/WRI/documentos/url-df-brgaap-4t19vfinal/20-01-31_212525_df\%20br\%20gaap\%204t19.pdf>. Acesso em: 18 mai. 2020. 